\title{
A UTILIZAÇÃo DE FITOTERAPIA NO COTIDIANO DE UMA POPULAÇÃO RURAL
}

\author{
THE PHYTOTERAPY UTILIZATION IN THE RURAL POPULATION ROUTINE
}

\section{LA UTILIZACIÓN DE LA FITOTERAPIA EN EL COTIDIANO DE UNA POPULACIÓN RURAL}

Helena Aparecida de Rezende* Maria Inês MonteiroCocco**

Rezende HA, Cocco MIM. A utilização de fitoterapia no cotidiano de uma população rural. Rev Esc Enferm USP 2002; 36(3): 282-8.

\section{RESUMO}

Esta pesquisa tem como objetivos estudar o uso da fitoterapia, em uma população da zona rural no interior de MG; identificar as plantas utilizadas com maior freqüência e formas de uso e comparar os seus efeitos com aqueles descritos na literatura. Foram entrevistadas 33 pessoas em 1997. Em relação às plantas fitoterápicas conhecidas pelos entrevistados foram citadas 106, sendo 60 efetivamente utilizadas. A transmissão do conhecimento referente ao seu uso ocorreu basicamente dos avós para os filhos e netos. A fitoterapia foi utilizada com fins semelhantes aos descritos na literatura, visando à prevenção e tratamento das doenças.

PALAVRAS-CHAVE: Fitoterapia. Enfermagem em saúde pública. Plantas medicinais.

\begin{abstract}
The aims of this study are to analyze the use of phytoterapy and the context of its utilization in a rural areapopulation $M G$; to identify the herbs used with more frequency and their forms of use; to compare the results of medicinal herbs with that described in literature. Thirty three people were interviewed in 1997. About the phytoterapy herbs known by them 106 different species were quoted, and 60 of them were effectively used in their routine. The transmission of knowledge related to the use of the herbs occurred basically from grandparents to the children. The phytoterapy was used by the population studied with similar purposes described in the literature aiming the prevention and treatment of diseases.
\end{abstract}

KEYWORDS: Phytoterapy. Public health nursing. Plants, medicinal.

\section{RESUMEN}

El objetivo de esta pesquisa es estudiar lo empleo de la fitoterapia en una población de la área rural en lo interior de Minas Gerais, identificar las plantas utilizadas con mayor frecuencia e comparar los resultados con lo descrito en la literatura. Fueran entrevistadas 33 personas en 1997. Fueran citadas 106 plantas conocidas por los entrevistados y 60 que son efectivamente utilizadas. La transmisión de los conocimientos referente a lo uso paso de los abuelos para los hijos y nietos. La fitoterapia fue usada para finalidad semejante a de la literatura, con la finalidad de prevención y tratamiento de las enfermedades.

PALABRAS-CLAVE: Fitoterapia. Enfermería de salud publica. Plantas medicinales.

Enfermeira - Portugal. Projeto de Iniciação Científica financiado pelo SAE-UNICAMP, 1997/98.

** Enfermeira - Professora Assistente Doutora - Universidade Estadual de Campinas - UNICAMP. FCM. Departamento e Enfermagem. Grupo de Estudos e Pesquisa Saúde e Trabalho e do PRAESA - Laboratório de Estudos e Pesquisas em ráticas de Educação e Saúde da Faculdade de Educação / UNICAMP. inesmon@obelix.unicamp.br 


\section{INTRODUÇÃO}

A utilização da fitoterapia, que significa o tratamento pelas plantas, vem desde épocas remotas. A referência mais antiga que se tem conhecimento do uso das plantas data de mais de sessenta mil anos. As primeiras descobertas foram feitas por estudos arqueológicos em ruínas do Irã. Também na China, em 3.000 a.C., já existiam farmacopéias que compilavam as ervas e as suas indicações terapêuticas. A utilização das plantas medicinais faz parte da história da humanidade, tendo grande importância tanto no que se refere aos aspectos medicinais, como culturais ${ }^{(1)}$.

No Brasil, o surgimento de uma medicina popular com uso das plantas, deve-se aos indios, com contribuições dos negros e europeus; na época em que era colônia de Portugal, os médicos restringiam-se às metrópoles e na zona rural e/ou suburbana cuidava a população recorria ao uso das ervas medicinais. A construção desta terapia alternativa de cura surgiu da articulação dos conhecimentos dos indígenas, jesuítas e fazendeiros. Este processo de miscigenação gerou uma diversificada bagagem de usos para as plantas e seus aspectos medicinais, que sobreviveram de modo marginal até a atualidade(2).

O conflito entre as formas de cura alternativa e o saber científico ocorre a partir do momento em que os leigos exerciam formas alternativas de cura, e este conhecimento era, em geral, desvinculado do saber acadêmico, sendo então considerado ilegítimo. O uso das práticas alternativas em saúde tem persistido, entre outros motivos, pela dificuldade no acesso à assistência de saúde para parte da população, que não tem suas demandas e necessidades atendidas, que são parcialmente supridas pelo uso das terapias alternativas e também por opção pessoal.

A medicina oficial aprendida nas faculdades apresentou, em geral, até recentemente, uma perspectiva tecnicista, que vê o cliente de modo fragmentado; de modo diverso das terapias alternativas, que têm uma visão mais abrangente do homem.

A Organização Mundial da Saúde (OMS) já reconhece, na atualidade, a importância da fitoterapia, sugerindo ser uma alternativa viável e importante também às populações dos países em desenvolvimento, já que seu custo é diminuido. Pesquisas realizadas nas universidades brasileiras já identificaram mais de 350 mil espécies vegetais, o que permite uma ampla variedade aos possiveis usos medicinais. Entre tantas espécies, apenas dez mil têm algum uso medicinal conhecido. No Brasil há cem mil espécies catalogadas, sendo apenas dois mil com uso científico comprovado $^{(1)}$.
A fitoterapia utiliza-se das diversas partes das plantas, como raizes, cascas, folhas, frutos e sementes, de acordo com a erva em questão. Há também diferentes formas de preparação destas plantas, sendo o chá a mais utilizada, preparado por meio da decocção ou infusão. No primeiro processo a planta a ser utilizada é fervida junto a água, já no segundo a água é fervida sozinha e depois colocada sobre a planta, quando são liberados os seus princípios terapêuticos(3).

Desta maneira, é importante a participação dos profissionais de saúde nesta área, visando uma integração do conhecimento utilizado pelo sistema de saúde oficial ao popular, pois as terapias alternativas têm muito a oferecer, podendo contribuir com as ciências da saúde, além de possibilitar ao indivíduo relativa autonomia em relação ao cuidado com a sua saúde.

O Brasil deve assumir uma posição clara de defesa de seu patrimônio biológico perante a comunidade internacional para evitar sua destruição. Há vários casos de países que exploram espécies vegetais de grupos indigenas do Amazonas para a produção de medicamentos(4). Há uma série de remédios que estão sendo pesquisados por universidades e centros de pesquisas brasileiros. $\mathrm{O}$ químico Walter Mors, professor aposentado da Universidade Federal do Rio de Janeiro (UFRJ), pesquisa há dez anos o uso da erva botão (Eclipta prostrata) como antiofidico. Outro pesquisador, o químico Benjamim Gilbert, da divisão farmacêutica da Fundação Osvaldo Cruz, testa uma erva que é largamente usada pelos caboclos da Amazônia, o chá de picão (Bidens pilosa) para o tratamento de malária e hepatite B. O químico Angelo da Cunha Pinto, da UFRJ, orienta uma pesquisa sobre o poder da sucuuba (Himathantus sucuba) no tratamento de tumores; em laboratório, o extrato da planta conseguiu reparar o DNA de levedura(5).

Face ao exposto, é de fundamental importância a realização de estudos detalhados das plantas existentes no Brasil, com o objetivo de identificar sua forma de uso visando a obtenção de patente, o que beneficiaria o país e a população.

Em estudo realizado sobre o uso da fitoterapia pela população do município de Campina Grande Paraíba, em que foi realizada visita domiciliária com 782 famílias, para entrevista e coleta de plantas, em $82,9 \%$ havia uma pessoa que era considerada "especialista", usando as plantas para sua família e para ela; $87,2 \%$ haviam aprendido com a família sobre o uso das plantas. As plantas foram utilizadas para problemas "... gastrointestinais $(21,1 \%)$, garganta, nariz e pulmões $(18,2 \%)$, febres e gripes $(13,3 \%)$, psiconeurológicos $(8,3 \%)$, cardíacos e circulatórios $(6,5 \%) "$. 0 chá foi citado como a forma mais freqüente de uso das plantas $(63,4 \%)^{(6)}$. 
$\mathrm{Na}$ área de enfermagem e fitoterapia Nogueira é uma referência fundamental desde o início da década de oitenta, quando defendeu sua tese de livre docência sobre "Fitoterapia popular e enfermagem comunitária" na Escola de Enfermagem da Universidade de São Paulo, em 1983.

Em pesquisa realizada com mulheres que utilizavam os Centros de Saúde da região de São Paulo, no período de 1979 a 1981 , a autora relata que $84,6 \%$ das entrevistadas utilizavam plantas medicinais, com informações obtidas na maior parte das vezes na família. "O conhecimento sobre fitoterapia foi influenciado pela idade e escolaridade (as mais velhas e com menos escolaridade sabiam mais) [...] e as mais velhas e moradoras na região, por conhecerem mais as plantas locais usavam-na mais". $\mathrm{Na}$ - maioria das vezes as plantas foram utilizadas na forma de chá $(62,9 \%)$, sendo seu uso mais freqüente para problemas digestivos $(17,5 \%)$, respiratórios e cavidade oral $(15,1 \%)$, problemas ginecológicos/obstétricos $(10,3 \%)^{(7)}$.

No Brasil o uso da fitoterapia tem sido paulatinamente incorporado aos serviços públicos de saúde. Na região de Campinas(SP), vem sendo utilizada e analisada desde 1990, em Centros de Saúde pertencentes a região leste, onde médicos, enfermeiros, dentistas e farmacêuticos são orientados sobre os procedimentos da terapêutica e as formas de apresentála aos pacientes, como uma opção para tratamento(8). Atualmente, alguns fitoterápicos padronizados são utilizados em todos os Centros de Saúde de Campinas; em Hortolândia(SP), município próximo a Campinas, a fitoterapia é largamente utilizada no Programa de Saúde da Família(9)

Os profissionais de enfermagem podem incentivar a utilização deste conhecimento em diferentes locais, inclusive nas áreas mais carentes de recursos de saúde, associado ao saber da população local, na tentativa de enriquecer o estudo da fitoterapia e ainda oferecer à população subsídios para uma vida melhor, orientando quanto à forma mais adequada de utilização das plantas.

\section{OBJETIVOS}

Descrever o uso da fitoterapia em população rural do interior de Minas Gerais;

Identificar as plantas utilizadas com maior freqüência, motivo e sua forma de utilização;

Comparar o uso efetivo da fitoterapia com o uso descrito -na literatura.

\section{METODOLOGIA}

Esta pesquisa descritiva exploratória foi realizada nos meses de julho, agosto, setembro e dezembro de 1997, no município de Santa Rita de Caldas, no sul de Minas Gerais, localizado a aproximadamente $200 \mathrm{Km}$ de Campinas, que possui uma população de 9.258 habitantes (censo de 1991) sendo que 55\% (5.081 habitantes) se concentram na zona rural e 45\% (4.167 habitantes), na zona urbana. O município possui uma área total de 503 $\mathrm{Km}^{2}$ e as principais fontes de renda são a agricultura e a pecuária.

O interesse pela pesquisa em Santa Rita de Caldas deveu-se ao fato de uma das pesquisadoras ser moradora da zona rural desta cidade, tendo conhecimento da situação de carência do município em relação à assistência de saúde.

A população escolhida para a realização deste estudo reside na zona rural do municipio e a amostra foi de trinta e três entrevistados, tendo como critério de inclusão fazer uso da fitoterapia. A partir do conhecimento da população residente na área rural de uma das pesquisadoras, foram contatadas pessoas que utilizavam os fitoterápicos, que informaram sobre outras pessoas que também conheciam e/ou faziam uso de plantas. Foi utilizado como instrumento para a coleta de dados a entrevista semi-estruturada. Antes de iniciar as entrevistas foi realizado um pré-teste do instrumento com três pessoas. Foi feito também um diário de campo após cada entrevista, com o objetivo de facilitar a análise dos dados.

As entrevistas tiveram a duração média de 30 minutos, variando de 20 a 90 minutos, tendo sido realizada na casa dos entrevistados. A pesquisa foi avaliada pela Comissão de Ética em Enfermagem do HC - Unicamp, os entrevistados deram o consentimento verbal para a realização da mesma.

\section{RESULTADOS E DISCUSSÃO}

Foram entrevistadas 33 pessoas sendo dezoito do sexo masculino e quinze do sexo feminino, conforme tabela 1 .

Tabela 1 - Distribuição da população segundo faixa etária. Santa Rita de Caldas (MG), 1997.

\begin{tabular}{|c|c|c|c|c|}
\hline FAIXA ETÁRIA & Sexo & & & $\%$ \\
\hline & $\mathbf{M}$ & $\mathbf{F}$ & Total & \\
\hline $25-34$ & - & 01 & 01 & 3.0 \\
\hline $35-44$ & 01 & 02 & 03 & 9.1 \\
\hline $45-54$ & 03 & 06 & 09 & 27.3 \\
\hline $55-64$ & 07 & 03 & 10 & 30.3 \\
\hline $65-74$ & 07 & 03 & 10 & 30.3 \\
\hline TOTAL & 1.8 & 15 & 33 & 100,0 \\
\hline
\end{tabular}


Por meio da tabela 1 pode-se observar que o maior número de entrevistados $(60.6 \%)$ está na faixa etária entre 55 e 74 anos. No horário em que foi realizada a entrevista, havia poucos jovens em casa, que geralmente estavam no trabalho rural.

Em relação à naturalidade, vinte e oito entrevistados são naturais de Santa Rita de Caldas; um entrevistado é de Governador Valadares (MG), dois são de Ipuíuna (MG), dois são de Caldas (MG), sendo as duas últimas cidades vizinhas de Santa Rita de Caldas.

Observou-se na pesquisa realizada que a maior parte dos homens entrevistados tem o curso primário completo $(33,3 \%) ; 27,8 \%$ o primário incompleto; $22,2 \%$ o ensino fundamental incompleto (antigo $1^{\circ}$ grau) e apenas um tem curso superior (cursou agronomia na UFMT). É interessante notar que apesar de ser uma região rural nenhum dos entrevistados é analfabeto.

Entre as mulheres entrevistadas 33,3\% têm o curso primário incompleto; $26,7 \%$ o primário completo; $20 \%$ o ensino fundamental incompleto e $20 \%$ são analfabetas. Todas as mulheres eram casadas, tinham filhos e se dedicavam exclusivamente ao serviço doméstico.

Vinte e dois entrevistados referiram usar plantas medicinais (chás e outros preparados) para problemas de saúde como gripe, dor de cabeça, ou seja, em casos de pouca urgência e de fácil controle e, em casos mais graves, procuram a farmácia e/ou Centro de Saúde. Destes, cinco referiram procurar a benzedeira.

Quatro entrevistados referiram usar mais a farmácia e/ou Centro de Saúde, sendo dificil utilizaremse de remédios preparados a partir de ervas medicinais. Destes, um entrevistado referiu procurar também a benzedeira.

Dois entrevistados referiram usar mais a farmácia e/ou Centro de Saúde e usam algumas plantas como complemento do tratamento médico e cinco entrevistados utilizam-se exclusivamente dos remédios caseiros.

Como se pode observar, a maioria dos entrevistados utiliza os dois recursos de saúde abordados neste estudo: a fitoterapia em casos de problemas de saúde mais simples e que podem ser resolvidos no próprio domicílio e buscam auxílio em casos mais graves (é interessante notar que este auxilio pode ser tanto em farmácia como o Centro de Saúde). Um dado que merece ser destacado é o aparecimento da benzedeira que foi citada por seis entrevistados, como um outro recurso complementar aos já citados. Com esses dados pode-se concluir que na população estudada há uma ligação estreita com a fitoterapia.

Quatorze entrevistados procuram atendimento médico para o cônjuge, filho (a) ou para eles mesmos para o tratamento de doenças crônicas como reumatismo, diabetes, problemas de coluna, problemas cardíacos.
Treze procuram atendimento médico só em casos de urgência e/ou mais graves como pneumonia, dores agudas; um entrevistado além de procurar atendimento médico nos casos mais graves também faz tratamento para problemas cardíacos.

Cinco procuram atendimento médico de rotina.

Este dado mostra mais uma vez que a procura por atendimento médico se dá em casos mais sérios de saúde como tratamento de doenças crônicas (diabetes, doenças cardíacas, entre outros), ou nos caso de urgência e agudos (pneumonia, por exemplo), que não são resolvidos em casa.

Para facilitar o estudo, as plantas fitoterápicas foram divididas em dois blocos: o primeiro é o das plantas conhecidas pelos entrevistados, mas que não são utilizadas; e o segundo é o das plantas utilizadas pelos mesmos. Muitas plantas foram mencionadas nos dois blocos, pois alguns entrevistados citaram as mesmas como sendo apenas conhecidas e outros como sendo utilizadas.

Das plantas fitoterápicas conhecidas pelos entrevistados foram citados 106 nomes diferentes e destas, algumas se repetiram e muitas foram citadas apenas uma vez. As plantas conhecidas pelos entrevistados que foram citadas com maior freqüência foram: elevante (citada 9 vezes), macela (8), picão (8), poejo (8), alecrim (7), assapeixe (7), erva cidreira (7), losna (7), arruda (6), cibalena (6), dente-de-leão (6), folha de goiaba (6), hortelã (6), malva (6), quebra pedra (6), unha de vaca (6), velame (6), carapiá (5), carobinha (5), chapéu de couro (5), serralha (5), sete sangrias (5), boldo (4), casca de anta(4), cavalinha (4), erva doce (4), folha de café (4), gervão (4), jurubeba (4), solda(4), tansagem (4).

Das plantas fitoterápicas relatadas como sendo efetivamente utilizadas pelos entrevistados foram citados sessenta nomes, sendo que, destes, alguns foram relatados mais de uma vez; sendo as mais freqüentes: hortelã (citada por 11 pessoas), poejo (10), carqueja (08), erva doce (08), erva cidreira (07), boldo (06), folha de laranjeira (06), limão (06), camomila (5), folha de café (05), folha de cana (05), cabelo de milho (04), eucalipto (04), alecrim (03), arnica (03), assapeixe (03), capim santo (03), folha de abacate (03), folha de lima (03), gravatá (03) e chapéu de couro (03).

A seguir estão relacionadas as indicações de uso das plantas utilizadas pelos entrevistados e o seu efeito curativo segundo referências bibliográficas:

HORTELÃ: foi citada em onze entrevistas. É utilizada como calmante. Combate a cólica em crianças e é vermífugo. Nestes casos é feito o chá, podendo também ser usado na preparação de xarope no combate a gripe, junto com o limão ou a laranja e o eucalipto. $\mathrm{Na}$ literatura a hortelã apresenta propriedades antiespasmódicas, sendo empregada nos casos de 
flatulência, icterícia, vômitos, cólicas uterinas. É usado como vermífugo. Combate as secreções nasais e favorece a expectoração(10)

POEJO: foi citado em dez entrevistas. Combate a tosse (na forma de chá), podendo ser utilizado como componente de xaropes no combate a tosse, gripe e bronquite, semelhante ao encontrado na literatura ${ }^{(3,10)}$

CARQUEJA: foi citada em oito entrevistas. Combate a dor de estômago e ajuda a controlar o diabetes. Nestes casos deixar as folhas em água durante algumas horas e beber. Ajuda a combater o colesterol, previne a "ressaca" e auxilia no emagrecimento. Na literatura a carqueja é empregada na forma de chá para anemia, cálculos biliares, diarréias, enfermidades da bexiga, do figado, dos rins, má digestão, icterícia, inflamação das vias urinárias, diabetes; no caso de inflamações da garganta o gargarejo é eficaz ${ }^{(10)}$.

ERVA DOCE: foi citada em oito entrevistas. Combate a cólica, a prisão de ventre e a dor de cabeça; é utilizada na forma de chá. Na literatura tem aplicações semelhantes ${ }^{(10)}$

ERVA CIDREIRA: foi citada em sete entrevistas. Combate a insônia e a dor de estômago, além de ter um efeito calmante; é utilizada na forma de chá. Na literatura tem aplicações semelhantes ${ }^{(10)}$.

BOLDO: foi citado em seis entrevistas. É utilizado contra a dor de estômago, azia e má digestão. Pode ser utilizado como chá ou apenas macerar a planta em água e beber. Na literatura, tem aplicações semelhantes $(3,10)$

FOLHA DE LARANJEIRA: foi citada em seis entrevistas. É utilizada contra resfriado e tosse, na forma de chá. Na literatura as folhas, flores e cascas de laranjeira são estimulantes, tônicas e sudoríficas (provocam o suor), são indicadas nas contrações dos músculos, indigestões e cólicas ${ }^{(11)}$.

LIMÃO: foi citado em seis entrevistas. Seu uso prolongado serve como depurativo do sangue, podendo ser utilizado na preparação de xaropes para combater a tosse. Na literatura foram encontradas diversas aplicações, como no combate à acne, afta, apendicite, asma, alcoolismo, amenorréia, amigdalite, anemia, angina do peito, bócio, broncopneumonia, faringite, conjuntivite, gripe ${ }^{(10)}$

CAMOMILA: foi citada em cinco entrevistas. É utilizada como calmante. Na literatura é indicada em perturbações estomacais, diarréia, naúseas, infecções urinárias (como chá). É usada também em compressas quentes no combate a reumatismo(10)

FOLHA DE CAFÉ: foi citada em cinco entrevistas. Em todas é utilizada no combate a dores reumáticas e das articulações (é feito um banho com o chá, no local da dor), sendo semelhante seu uso descrito na literatura(11).
FOLHA DE CANA: foi citada em cinco entrevistas. Combate afecções renais e dor de estômago, podendo ser associada a outras plantas como à folha de abacate e à folha de lima e feito um chá. Na literatura é empregada nas afecções renais e da bexiga, é tônico, mantém a força muscular ${ }^{(10,11)}$

CABELO DE MILHO: foi citado em quatro entrevistas. Combate afecções renais e infecção urinária, sendo utilizado na forma de chá, juntamente com outras plantas, como a folha de cana. Na literatura seu fruto é usado como diurético, o cabelo de milho é empregado contra afecções da bexiga e rins, cistite, disúria e albuminúria, usa-se na forma de chá(11).

EUCALIPTO: foi citado em quatro entrevistas. É utilizado no preparo de xarope para combater a gripe. As suas folhas, se fervidas em água, juntamente com as folhas de batata doce e café, combatem as dores nas articulações. Na literatura o eucalipto é utilizado na forma de chá nos casos de asma, bronquite, diarréia, sinusite ${ }^{(10,11)}$

ALECRIM: foi citado em três entrevistas. É usado como calmante e tônico para o coração, semelhante ao uso proposto na literatura $(10,11)$

ARNICA: citada em três entrevistas. Utilizada como analgésico, na forma de chá ou banho para dor muscular (deixar a água ferver com as folhas e depois de esfriar fazer o banho). Na literatura os rizomas e as flores são empregados externamente nos casos de traumatismo e internamente para estimular os batimentos cardíacos e circulação(3).

ASSAPEIXE: citado em três entrevistas. Utilizado no controle de diabetes (como chá). Na literatura o assapeixe tem as mesmas indicações citadas pelos entrevistados ${ }^{(11)}$.

CAPIM SANTO: foi citado em três entrevistas. É utilizado no combate a hipertensão e como analgésico (como chá). O capim-santo não foi encontrado na literatura.

CHAPÉU DE COURO: citado em três entrevistas. Utilizado como depurativo do sangue (como chá), de forma semelhante a encontrado na literatura( ${ }^{(3)}$.

FOLHA DE LIMA: foi citada em três entrevistas. Combate, associada à folha de cana e ao cabelo de milho, afecções renais e dor de estômago. É usada na forma de chá. De acordo com a literatura a lima é indicada contra febres, tendo também um efeito diurético. O chá da casca e das folhas aumenta a pressão e combate as perturbações do estômago".

FOLHA DE ABACATE: foi citada em três entrevistas. Combate a infecção urinária quando associada à folha de cana e ao cabelo do milho; quando associada ao inhame do brejo, combate as dores do reumatismo. Na literatura é referida como diurético, contra o artritismo e além de eliminar cálculos renais e do figado. Devem ser utilizadas as folhas secas, pois 
as verdes podem causar taquicardia(11).

GRAVATÁ: foi citado em três entrevistas. É utilizado nos casos de gripe e tosse, na forma de xarope. Na literatura a fruta assada é citada como xarope contra a tosse(11).

A população estudada conhece e utiliza uma quantidade grande de ervas medicinais. Pode-se observar que o uso (3,6,7,10-12) e forma de preparação(6,7) da maioria das plantas citadas neste trabalho têm muita semelhança com o descrito por outros autores. Muitas vezes houve dificuldade na identificação da planta correta, pois a mesma espécie recebe nomes diferentes.

Cinco entrevistados utilizam e têm em seus domicílios livros de plantas medicinais(10,11). Isto mostra a procura pelas plantas e a busca de informações mais precisas e com base mais apurada pelos entrevistados, sugerindo, mais uma vez, a necessidade de estudos mais aprofundados nesta área.

Em relação ao aprendizado, 22 entrevistados referiram que o conhecimento e o uso destas plantas foi passado de geração a geração, ou seja, aprenderam com os pais e avós (transmissão intergeracional), de modo semelhante ao encontrado por outros autores $(6,7)$ Muitos disseram que quando eram crianças não existia farmácia na localidade onde residiam e o único recurso de saúde existente eram as plantas medicinais. Os avós geralmente eram ervateiros, as avós eram parteiras e benzedeiras, e na horta havia várias espécies de plantas. Destes entrevistados, um deles referiu ter aprendido o uso de plantas também na faculdade quando cursou agronomia no Mato Grosso; destes, dois também referiram ter conhecido mais ervas com os livros sobre as plantas.

Dois entrevistados além de terem aprendido com os pais também tiveram contato com as plantas através dos vizinhos. Um referiu ter aprendido o uso de ervas medicinais com os índios, quando morou no Paraná.

Dez entrevistados referiram ter aprendido com amigos e vizinhos, destes dois também aprenderam com a benzedeira.

De modo semelhante ao encontrado em outros autores que estudaram o uso da fitoterapia pela população, as plantas medicinais são encontradas no quintal ou próximo a sua residência $(6,7)$. Nesta pesquisa 27 entrevistados referiram ter estas plantas no quintal, na horta; destes treze referiram procurar também com amigos, conhecidos e vizinhos, as mais dificeis de serem encontradas. Quatro entrevistados buscam as plantas somente com os vizinhos, pois não possuem nenhuma espécie em casa e outros dois, nas matas, pastagens e campos da redondeza. Todos os entrevistados procuram as plantas na região, com conhecidos, amigos, vizinhos; desta forma plantas de outras regiões foram pouco citadas neste trabalho.

Quanto às formas de preparação citadas pelos entrevistados, encontramos: chá (a planta é fervida em água); xarope (pode ser feito com a mistura de outras plantas, fervido com açúcar, até ficar um caldo); banho (geralmente a planta é fervida em água para lavar o local. É utilizada no combate a dores e feridas), emplastro (é feita uma pasta que é aplicada no local dolorido), óleo (feito com a planta fervida para extrair o óleo. Utilizado nas dores musculares e feridas); pomada ou ungüento (socar a planta em pilão, misturar vaselina e aplicar no local da afecção); maceração da planta em água para ser ingerida (geralmente para plantas muito amargas).

Na literatura as formas de preparação citadas são:

Decocção ou cozimento: o cozimento é resultante da decocção, que constitui a ação de ferver uma substância. Após a decocção, o líquido é coado e filtrado(12)

- Infusão: visa obter uma bebida mais leve que a decocção, utilizando as partes das plantas que podem ser prejudicadas pelo cozimento (folhas, flores, raízes). O vegetal é cortado, sendo vertido sobre ele água fervente e é tampado em seguida. O chá pode ser feito tanto a partir da infusão quanto da decocção, dependendo do tipo de planta(12)

- Maceração: visa obter princípios ativos solúveis, em toda a sua integridade; as plantas são colocadas em um recipiente com água fria, álcool, vinagre (para evitar decomposição) ou outro líquido e aí deixadas a macerar na temperatura ambiente por horas, dias ou semanas, sendo depois $\operatorname{coadas}^{(12)}$.

Unguiento: é resultante da mistura das ervas com uma substância gordurosa (vaselina, lanolina, ou ainda, com gordura animal(12).

Dos trinta e três entrevistados, vinte referiram usar estas plantas somente quando se sentem mal ou doentes; treze usam sempre, tanto para prevenir problemas de saúde, como para curar algum distúrbio ou doença.

Por meio dos dados obtidos pode-se observar que as plantas são utilizadas, pela maior parte dos entrevistados, tanto em casos agudos (para curar problemas de saúde mais "leves" como gripe) quanto em casos crônicos.

E importante destacar que há uma troca de conhecimentos entre as pessoas em relação ao uso de fitoterápicos, de modo semelhante ao encontrado em outro estudo(6), pois a maioria dos entrevistados (28) referiu indicar o uso destas plantas para vizinhos, amigos e familiares. Um destes entrevistados é benzedor e indica as plantas que conhece a qualquer pessoa que procurar.

Cinco entrevistados que fazem uso da fitoterapia referiram que não indicam o uso das plantas a ninguém.

Em relação à procura de informações, vinte e quatro entrevistados pedem informações sobre outras plantas e o seu uso para amigos, vizinhos, os pais, de 
modo semelhante ao relatado por outros autores(6,7) e até com benzedeiras, sendo que um consulta biólogos ebotânicos. Um, referiu só consultar o livro que utiliza e oito, referiram não pedir ajuda ou informações sobre outras plantas a ninguém, só usam o que já conhecem.

A maioria dos entrevistados utiliza as duas formas de tratamento, a fitoterapia e os medicamentos industrializados (uso referido em casos mais graves por grande parte dos entrevistados).

Por meio destes dados e do diário de campo feito em cada entrevista (baseado em observação, perguntas e depoimentos dos entrevistados), verificou-se que a população entrevistada tem muitas dúvidas no que se refere ao preparo, às dosagens e o desconhecimento de muitas plantas que poderiam utilizar para determinadas patologias. Neste contexto é que surge a necessidade de um profissional especializado nesta área, que tenha competência para transmitir a informação e orientar sobre o uso adequado destas plantas.

Concordamos com outros autores(7) que é importante a atuação da enfermeira neste campo, estudando as plantas fitoterápicas em cursos, pesquisas, detectando as necessidades desta e de outras populações no que se refira ao uso das plantas e ensinando à comunidade, carente de recursos de saúde, os conhecimentos adequados para uma melhor aplicação das mesmas.

\section{CONCLUSÃO}

Tendo como referência os dados obtidos na pesquisa realizada com a população da zona rural de Santa Rita de Caldas (MG) foi possivel constatar o uso de diferentes plantas no cuidado à saúde dos entrevistados.

Foram entrevistadas trinta e três pessoas sendo dezoito do sexo masculino e quinze do sexo feminino.

Das plantas conhecidas pelos entrevistados foram citadas 106 nomes diferentes, destas, algumas se repetiram e inúmeras foram citadas apenas uma vez. As plantas mais citadas foram: macela, elevante, losna, assapeixe, erva cidreira, poejo, sete sangrias, alecrim, chapéu-de-couro, solda, quebra-pedra, folha de goiaba, picão, folha de café, hortelã, erva doce, casca de anta, serralha, boldo, cibalena, arruda, carapiá, tansagem, unha de vaca, velame, carobinha, urtiga, dente-de-leão, cavalinha, malva.

Das plantas utilizadas pelos entrevistados foram referidos sessenta nomes. As plantas mais citadas foram: hortelã, poejo, carqueja, erva doce, erva cidreira, boldo, folha de laranjeira, limão, camomila, folha de café, folha de cana, cabelo de milho, eucalipto, alecrim, arnica, assapeixe, capim santo, chapéu-de couro, folha de lima, folha de abacate, gravatá.
As plantas utilizadas são as existentes na região, sendo a fitoterapia utilizada com fins semelhantes aos descritos na literatura, visando a prevenção e o tratamento de doenças. A transmissão de conhecimentos é intergeracional.

Consideramos que a participação dos profissionais de saúde e, especificamente, da enfermeira na orientação da população em relação ao uso da fitoterapia é de grande importância, tendo em vista a peculiaridade de cada planta e sua utilização adequada.

\section{REFERÊNCIAS BIBLIOGRÁFICAS}

(1) Saúde é Vital. Curas alternativas. São Paulo: Ed. Azul, ed. especial; 1991.

(2) Araújo AA. Medicina rústica. $3^{\mathrm{a}}$ ed. São Paulo: Brasiliense; 1979.

(3) Lainetti R, Brito ERS. A saúde pelas plantas e ervas do mundo inteiro. Rio de Janeiro: Ediouro; 1980.

(4) Braga PH. A patente que veio do índio. Folha de São Paulo 1997 jul 10; 15.

(5) Assunção JC. Floresta vira farmácia. Folha de São Paulo 1997 jul 10; 14.

(6) Amorim JA. Fitoterapia popular e a saúde da comunidade: diagnóstico para proposta de integração nos serviços de saúde em Campina Grande, Paraíba, Brasil. [tese] São Paulo (SP): Faculdade de Saúde Pública USP; 1999. Disponível em: http://bases.bireme.br/cgi-bin/wxislind.exe/iah/online > (19 abr. 2002)

(7) Nogueira MJC. Recursos naturais nas práticas caseiras de cuidados à saúde - utilização pela enfermeira. Rev Esc Enferm USP 1984; 18(2):177-86.

(8) Roveri A. Fitoterapia cresce na cidade. A Tribuna 1997 mar 30: 16.

(9) Cocco MIM. Reestruturação produtiva e o setor saúde: trabalhadores de enfermagem em saúde coletiva. [tese] Ribeirão Preto(SP): Escola de Enfermagem de Ribeirão Preto/USP; 1997.

(10) Balbach A. As plantas curam. São Paulo: EDEL; s/d.

(11)Bruning J. A saúde brota da natureza. 9.ed. Curitiba: Educa; 1990.

(12)Geraldes ZAS, Lim TA, Leite MMJ, Lemmi RCA, Fernandes MA. Medicamentos vegetais de origem popular e suas implicações na assistência e ensino de enfermagem. Rev Esc Enferm USP 1981; 15(3):247-55.

\section{Artigo recebido em 05/01/00}

Artigo aprovado em 01/07/02 